\title{
(127) SHAKING TABLE TESTS AND NUMERICAL ANALYSIS OF MOTION OF RIGID BODIES UNDER DYNAMIC EXCITATION
}

\author{
Tibor WINKLER ${ }^{1}$ ), Kimiro MEGURO²) and Fumio YAMAZAK( ${ }^{3}$ )
}

INTRODUCTION The dynamic response of bodies under earthquake excitation is rather complex, highly nonlinear phenomenon [1]. Analytical study of the problem is not feasible in case of interaction of numerous objects of arbitrary shape, exposed to random dynamic waves. The aim of the study is to find satisfactory agreement between experiment and numerical analysis, conducted on simple examples, on the basis of which the above described complex behaviour may be followed using the Discrete Element Method (DEM) [2].

\section{SHAKING TABLE TESTS}

Rectangular wooden blocks were tested under dynamic excitation. The specimens of the experiment are shown in Figure 1. The last but one column, "k", contains the scale multipliers, which relate the size of individual blocks to that of the reference block [No.3]. The last column shows the slenderness ratios.

Accelerometers, measuring horizontal and vertical acceleration, signals of which were recorded, and stored on floppy discs, were attached to the blocks. Particular record of the motion of block No.7 $(\mathrm{b} / \mathrm{h}=0.2)$ under $2 \mathrm{~Hz}$ input shaking is shown in Figure 2. Sinusoidal excitation in an increasing fashion was then applied, in response to which rocking motion of the blocks initiated In a few examples, in cases of blocks of small height and $b / h$, loss of stability was reached, the columns overturned. In addition to acceleration, video records, in two directions, were taken aiming later comparison of the actual behaviour to that

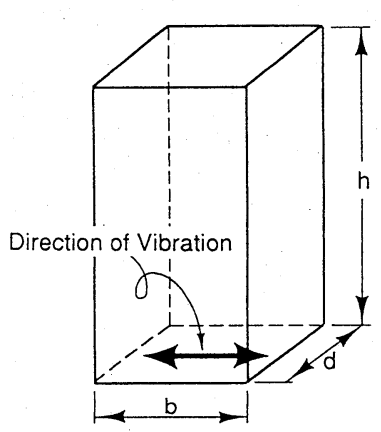

\begin{tabular}{c|c|c|c|c|c}
\hline \multirow{2}{*}{ Block } & \multicolumn{3}{|c|}{ Size $[\mathrm{cm}]$} & \multirow{2}{*}{$\mathrm{b} / \mathrm{h}$} \\
\cline { 2 - 5 } & $\mathrm{b}$ & $\mathrm{h}$ & $\mathrm{d}$ & & \\
\hline Block 1 & 30 & 100 & 50 & 2.0 & 0.3 \\
\hline Block 2 & 22.5 & 75 & 37.5 & 1.5 & 0.3 \\
\hline Block 3 & 15 & 50 & 25 & 1.0 & 0.3 \\
\hline Block 4 & 7.5 & 25 & 12.5 & 0.5 & 0.3 \\
\hline Block 5 & 25 & 50 & 25 & & 0.5 \\
\hline Block 6 & 20 & 50 & 25 & & 0.4 \\
\hline Block 7 & 10 & 50 & 25 & & 0.2 \\
\hline \hline
\end{tabular}

Figure 1 Rectangular Wooden Blocks Used in the Shaking Table Tests
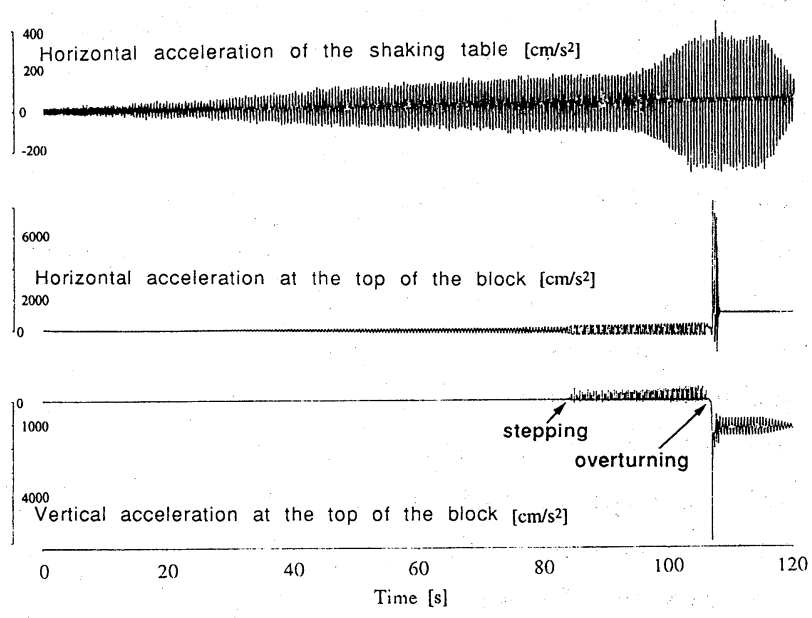

Figure 2 Acceleration Records of Block No.7 Under Base Motion [ $\mathrm{f}=2 \mathrm{~Hz}]$

3) Associate Professor, Institute of Industrial Science, University of Tokyo 
resulting from the computer simulation.

\section{DISCRETE ELEMENT ANALYSIS}

In preparation for the numerical analysis, material and energy dissipation parameters were identified as follows: stiffness of the wooden blocks was estimated [3] from wave propagation tests both in normal and transverse directions. Free vibration tests of all specimens were done. Using the already understood stiffness value, in the numerical analysis, the damping parameter was set such that the possible best agreement between experimental and computed time histories of the freely vibrating block could be achieved (contrast is seen in Figure 2). To supply exactly the same external dynamic effect as to which the specimens were exposed in the experiment, the horizontal motion of the shaking table was recorded and used as input motion in the computer analysis. Prior to the simulation of shaking table tests with the DEM, sufficiently small time increment had to be chosen to secure numerical stability (Figure 6).

RESULTS Input excitation amplitude at which rocking motion of bodies initiated was plotted versus frequency of the input wave. Figure 3 shows rocking criteria for four blocks of different $b / h$ ratio but of identical size ( $k=$ const.) yielded from the shaking table tests. In Figure 4 rocking criteria for four blocks, all of $b / h=0.3$ but of altered size, are seen. Comparison of rocking criteria, according to the shaking table experiment as well as to the computer analysis is show in Figure 7 The disagreement is, at any frequency, less then $10 \%$. Another way to confirm the applicability of the Discrete Element

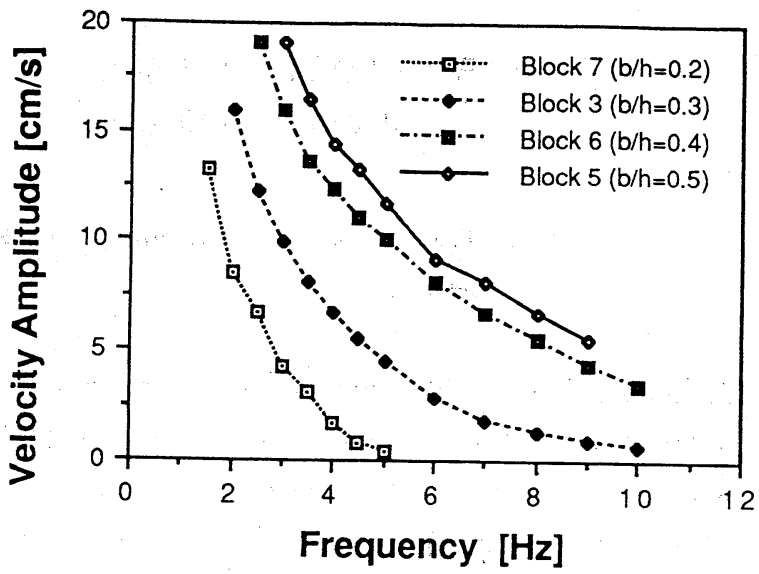

Figure 3 Rocking Criteria from the Shaking Table Tests

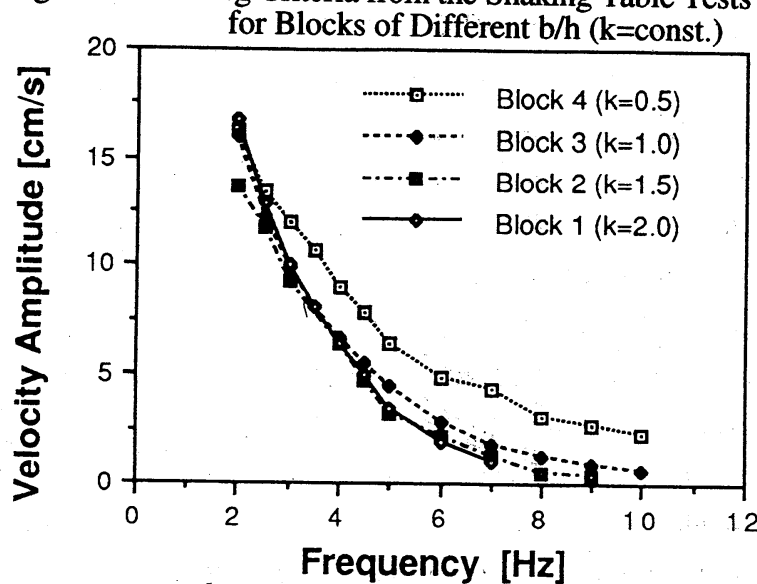

Figure 4 Rocking Criteria from the Shaking Table Tests for Blocks of Different Size (b/h=const.)

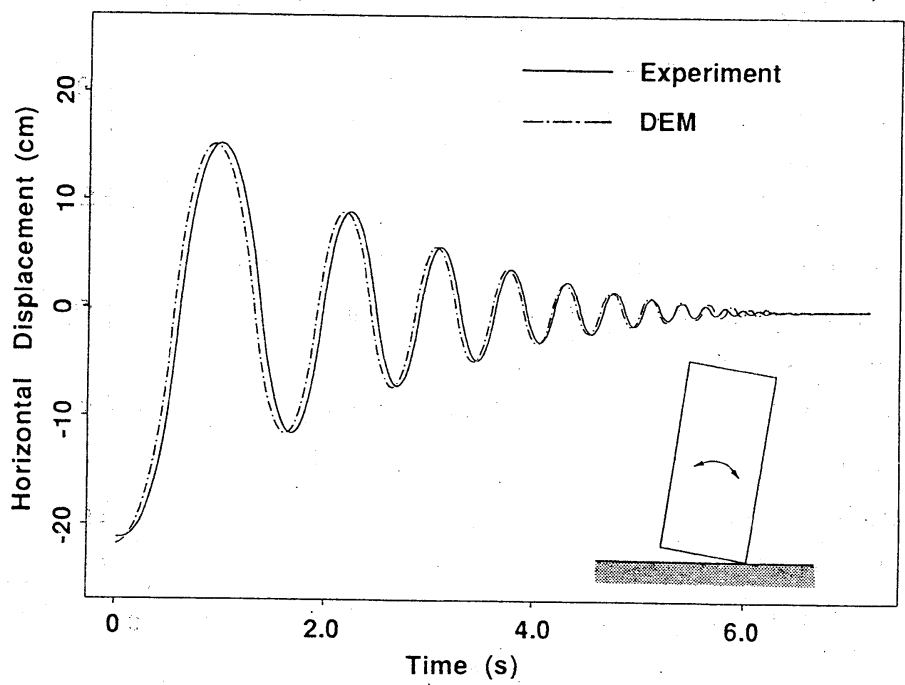

Figure 5 Damping Parameter Establishment on the Basis of Free Vibration Curve Matching 


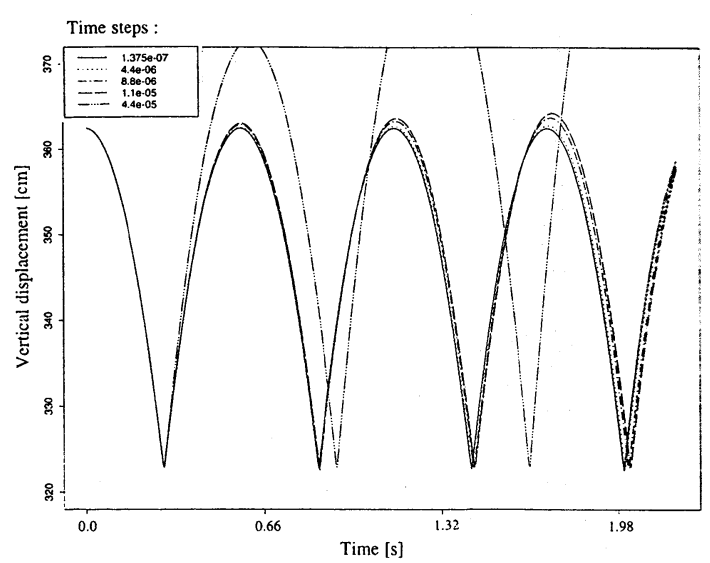

Figure $6 \quad$ Numerical Stability Test Oscillatory Motion of a Rigid Block Falling on Rigid Floor Under Gravitation

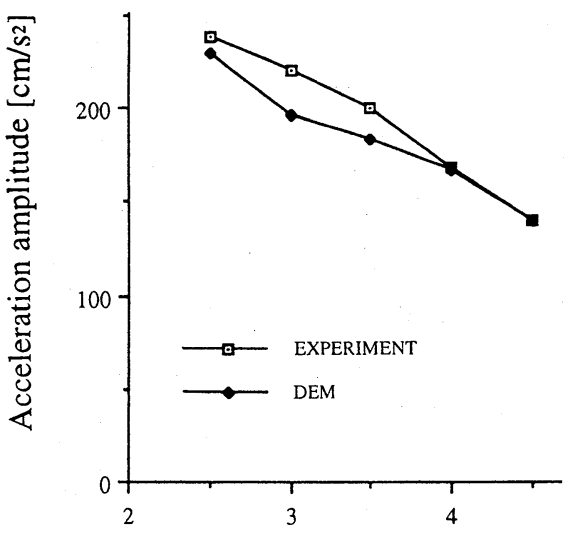

Frequency $[\mathrm{Hz}]$

Figure 7 Rocking Criteria for Block No.1 Experiment - DEM

Method is to compare video records, taken in the experiment, with real time computer animation. In Figure 8 is shown an example in which four rectangular columns, all of $b / h=0.3$, of varied size are tested in response to monotonically increasing sinusoidal wave. The response of the specimens, computed numerically, is essentially similar to that resulting from the experiment. The first four curves in Figure 9 show the angular displacements of individual blocks under the excitation shown on the bottom. Instants of overturning are noted (angle of rotation=90 deg.). Figure 10 shows substantial instants in the course of the simulation of the dynamic behaviour of two rigid blocks (block No.3: $\mathrm{b} / \mathrm{h}=0.3, \mathrm{~h}=50 \mathrm{~cm}$ ) in response to the excitation recorded in the shaking table test of the identical example (input motion seen below the snaps).

\section{CONCLUSION I $\mathrm{n}$ the contrast of} experimental and numerical results, the Discrete Element Method proved to be applicable to the studied problem. Should one wish to get not just qualitatively but as well quantitatively meaningful reference from the numerical analysis, the following points have to be paid attention to: Spring constant values have to be established at the highest possible accuracy, since most of the other parameters, such as damping, are dependent upon them (damping value to match free vibration time histories can be found for stiffness values varying in wide range). Parameters values, which govern contact judgment and updating, greatly influence the outcome, reasonable establishment of those is crucial.
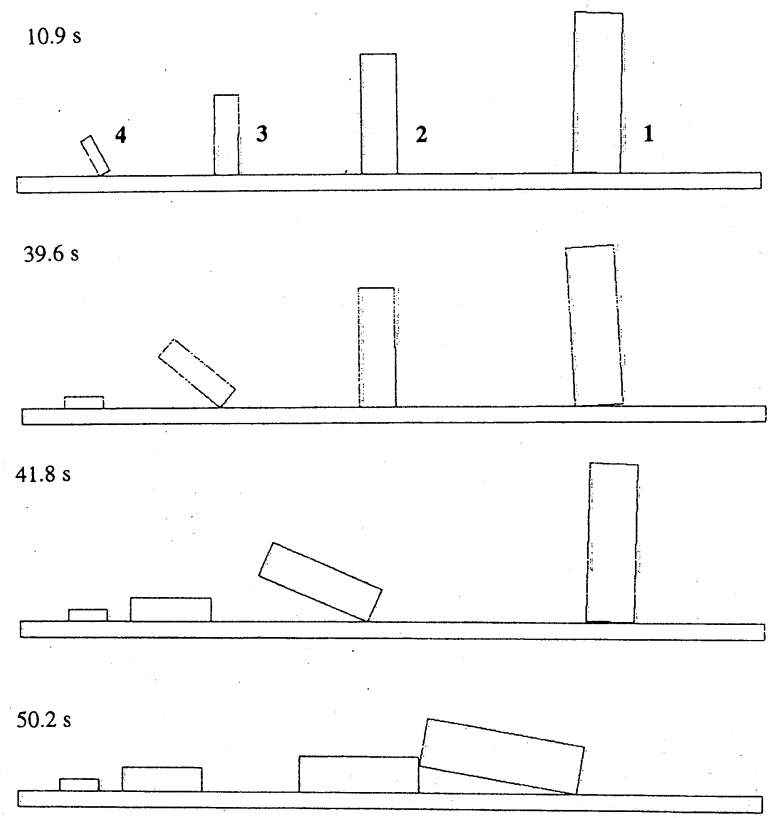

Figure 8 Animation of the Dynamic Response of Four Rigid Blocks of Different Size $(\mathrm{b} / \mathrm{h}=0.3)$ 


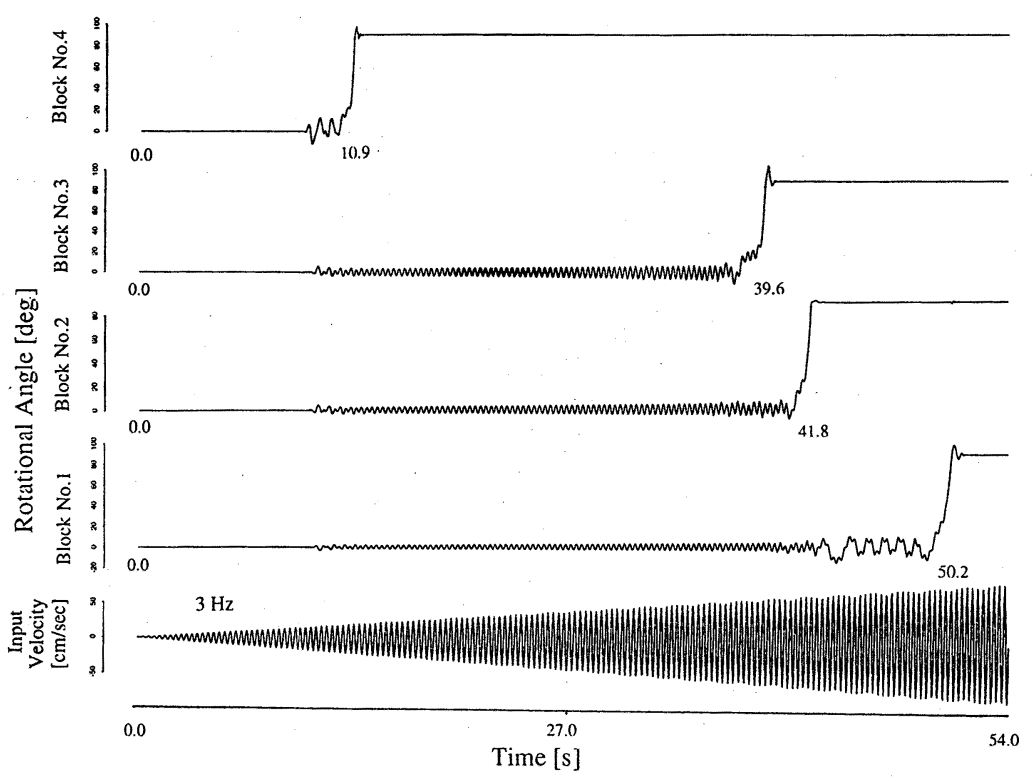

Figure 9 Angular Displacements of Four Rigid Blocks of Different Size Under Harmonic Base Motion $(\mathrm{b} / \mathrm{h}=0.3, \mathrm{f}=3 \mathrm{~Hz})$
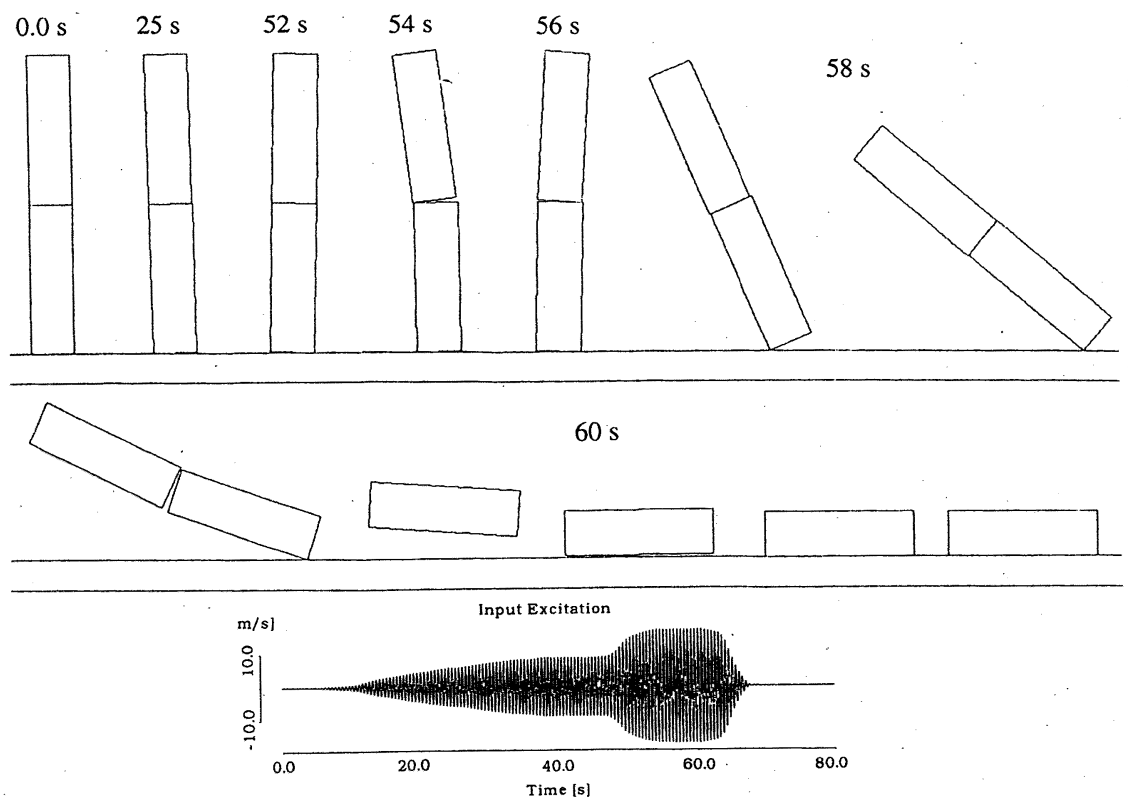

Figure 10 Animation of the Dynamic Response of Two Rigid Blocks to Harmonic Base Motion $(\mathrm{b} / \mathrm{h}=0.3, \mathrm{~h}=50 \mathrm{~cm}, \mathrm{f}=2 \mathrm{~Hz})$

References

[1] Y. Ishiyama. "Review and Discussion on Overturning of Bodies by Earthquake Motions" BRI Research Paper No.85, Building Research Institute, Ministry of Construction, June 1980.

[2] P.A. Cundall. "A Computer Model for Rock-Mass Behaviour" A report prepared under Contract number DACW 45-74-C006, for the Missouri River Division, U, S. Army Corps of Engineers, July 31, 1974.

[3] K. Meguro and M. Hakuno. "Fracture Analysis of Concrete Structures by Granular Assembly Simulation" Bulletin of the Earthquake Research Institute, University of Tokyo. Vol.63, Part 4, pp. 409-468, 1988 